\title{
The Application of Online Arbitration as an Alternative for Business Dispute Resolution During the COVID-19 Pandemic
}

\author{
Ning Adiasih ${ }^{1}$, Sandi Subagja ${ }^{2}$, Dhany Rahmawan ${ }^{3}$ \\ \{ning.a@trisakti.ac.id ${ }^{1}$, sandisubagja80@yahoo.co.id ${ }^{2}$, dhanyrahmawan66@gmail.com³ ${ }^{3}$, \\ Universitas Trisakti, Jakarta, Indonesia ${ }^{1,2,3}$
}

\begin{abstract}
The COVID-19 pandemic has brought changes in all areas, including the resolution of business disputes. One way of resolving business disputes can be through arbitration. The use of technology is a necessity in the transition from conventional dispute resolution models to online dispute resolution models, such as arbitration. Therefore, it is necessary to conduct a study to determine the possibility of applying online arbitration in practice and regulation in Indonesia, by comparing its application in the United States and China. In this study, the researchers used a comparative law method. In addition, the data collected were secondary data. In this study, it is found that during the COVID-19 pandemic, it is possible to apply online arbitration as an alternative to business dispute resolution as stipulated in Article 4 Paragraph 3 of Indonesia's Law No. 30/1999 that "In the event that it is agreed that dispute resolution is carried out through arbitration, it occurs in the form of an exchange of letters. Therefore, the sending of telex, telegram, facsimile, e-mail, or in other forms of communication means must be accompanied by a note of receipt by the concerned parties." It is reinforced by Article 31 Paragraph 1 that "The parties to a firm and written agreement are free to determine the arbitration procedure used in the examination of the dispute as long as it does not conflict with the provisions of the law." It includes conducting online arbitration. Online arbitration in the United States is organized by the American Arbitration Association (AAA). Since 2001, the organization has regulated that in carrying out online arbitration procedures, there is the main concept, namely that every online dispute will be made a site for the case. On the site, all files concerning cases and documents submitted by the parties will be stored. Meanwhile, in China, since 1 January 2015, the Online Arbitration Law has been enacted as a result of the development of e-commerce. Apart from that, China's Online Arbitration Law states that disputes that can be resolved through online arbitration are disputes arising from economic transactions and other trade transactions based on the agreement of the parties.
\end{abstract}

Keywords: Dispute Resolution; Online Arbitration

\section{Introduction}


The COVID-19 pandemic has brought changes in all areas, including the resolution of business disputes. One way of resolving business disputes can be through arbitration. The use of technology is a necessity in the transition from conventional dispute resolution models to online dispute resolution models, including arbitration.

The current development allows online commerce. Therefore, it also allows electronic dispute resolution. In the midst of anxiety about the legal system that does not accommodate technological developments and rapid progress, technology has given rise to the ideas of online dispute resolution. One of them is through online arbitration (e-arbitration).

Online arbitration is an attractive option in e-commerce dispute resolution, considering that the law wants it to be so. Issues that are still controversial currently are related to the competence of the courts and the applicable law in resolving disputes. The question that arises is whether creating a website that offers goods or services will make its creators liable to prosecution in other countries. The online business actors are also not sure whether the materials placed on their websites violate the law in other countries.

Arbitration has its respective procedures and the decision is final and binding. As a forum for dispute resolution, the status of arbitration courts is equivalent to the status of general courts. Each court stands alone. Besides, they are prohibited from intervening with each other. However, arbitration is a private court whose implementation costs are borne by the disputing parties.

As a private court, the presence of arbitration is not automatic. Arbitration can only be realized if its presence is agreed upon by the parties carrying out business transactions (commercial transactions). The agreement of the parties is called an arbitration agreement, in which arbitration can only be realized under an arbitration agreement. In other words, there is no arbitration without an arbitration agreement.

The parties to a business contract are free to determine the preferred judicial forum (choice of forum). The parties may choose a general court or an arbitration tribunal. If the parties choose a general court, then there is no need for a "general court agreement" when the business transactions carried out are national in nature. However, the parties need to have a general court agreement if the business transaction is international in nature. Furthermore, if the parties choose an arbitral tribunal, as has been mentioned previously, then the parties are required to have an arbitration agreement for both national and international transactions [1].

In this context, we can see the various characteristics of transactions on the internet. These characteristics are basically transactions across geographic boundaries, connecting individuals and business actors from various cultures that can give rise to disputes. Currently, the dispute is mostly very small in value but requires a fast resolution. However, the costs are not too expensive. For this reason, various efforts have been made, including providing online alternative dispute resolution, such as online arbitration [2].

Online arbitration and online alternative dispute resolution are not much different from traditional arbitration and conventional alternative dispute resolution. The difference is only in the method used, namely the use of electronic means in its implementation. In online arbitration, case registration, selection of arbitrators, submission of documents, deliberation of arbitrators in the case of an arbitration tribunal with more than one arbitrator, making decisions, and notification of decisions are made online [2].

Conventional business dispute resolution mechanisms are very limited by the geographical location and the law where business activities are carried out. The determination, of which law and jurisdiction have the authority to examine and adjudicate a dispute, often becomes a problem when the parties are about to conclude a contract. However, in conventional transactions, it is relatively easy to determine which law will be applied. 
The above conditions are very different when trading transactions occur in cyberspace. The question that often arises is which law and jurisdiction will be used if a dispute arises between the parties, whereas in cyberspace every interaction is not limited by territorial boundaries. Therefore, the need for an institution tasked with resolving any business disputes (e-commerce) is something that cannot be delayed any longer.

\section{Research Problem}

Considering that the world is currently being hit by the COVID-19 pandemic and technological advances are increasingly rapidly making people have ideas that have a very wide reach without being limited by distance and time, arbitration is an alternative dispute resolution outside the court that is in great demand, especially from business actors. Based on the brief description previously, there are several things that become problems in this study, namely as follows. How is the implementation of online arbitration in the United States and China? Can online arbitration be implemented in Indonesia referring to Indonesia's Law Number 30/1999 concerning Arbitration and Alternative Dispute Resolution (Law of Arbitration \& Alternative Dispute Resolution)?

\section{Methods}

This study used is normative-juridical research and a comparative law approach. The comparison method is carried out by collecting, analyzing, and describing ideas, doctrines, and institutions found in every developing legal system. Almost all of the systems are in the United States and China. Those systems are compared with the legal system in Indonesia to answer the possibility of applying online arbitration in Indonesia which was previously unknown.

\section{Discussion}

\subsection{Implementation of Online Arbitration}

In conducting online arbitration, the researchers apply the following steps.

\section{a) Beginning}

After the disagreement between the parties stipulated in the arbitration agreement cannot be resolved, the party can submit the case to arbitration, institution, or ad-hoc arbitration. The submission of the case by the applicant can be carried out via e-mail. If the arbitration institution has provided its website with an online form for litigation, the case can be registered online. In the event that the application is made via email, the arbitration institution or arbitrator must ensure that the applicant is the right person. In this communication, both the applicant and the respondent can request or refuse to conduct an online procedure. If the parties agree and according to the arbitration institution, in which both the applicant and the respondent have the capacity to undergo an online arbitration procedure, the online procedure 
can be carried out. Conversely, if the arbitration institution discovers the lack of capacity to conduct online arbitration, traditional arbitration procedures can be carried out.

\section{b) Written statements and documents}

At this stage, the parties must submit written statements and documents to the arbitrator and the opposing party in order to guarantee the principle of contradiction. In an e-commerce environment, the parties can present electronic evidence in their possession and physical evidence to support their arguments. Electronic documents can also be made available on special websites and provide an opportunity to search through www or transfer files in FTP format.

\section{c) Trial}

The law determines the arbitration process in writing. If necessary, an oral examination will be held. Therefore, document examination is the main thing, while the oral examination is carried out if necessary. In fact, technically, an electronic oral examination can be carried out. However, the cost of conducting trials electronically is very high.

The absence of an electronic trial will indeed cause difficulties. First, in a trial, it will be easy to find out what the parties want in a question-and-answer session. However, in an electronic environment without a trial, this must be carried out via e-mail exchange or through the use of IRC. This will make the principle of contradiction fulfilled. Second, in the event that eyewitnesses are needed, it seems that this will be difficult. Questions and answers with witnesses are necessary for a trial. It is doubtful whether the use of written testimony can meet the requirements.

\section{d) Online Deliberation}

In the online arbitration process, the verdict is not read aloud. After the decision is made, the parties will be notified online concerning the time and date of the decision publication. Furthermore, the decision will be sent using electronic means. Indonesia's Law of Arbitration and Alternative Dispute Resolution has not accommodated this. Article 55 of this law stated that "If the dispute examination has been completed, the examination will be closed immediately. Furthermore, a court day will be set to pronounce the arbitration award."

In addition, Article 57 further stipulates that "The decision shall be pronounced within 30 days after the examination is closed." Neither Indonesia's Law of Electronic Information and Transactions nor Indonesia's Law of Arbitration and Alternative Dispute Resolution has regulated the equivalence of the pronouncement of the decision in the online version. It is still questioned whether the use of internet relay chat (IRC) can be equated with pronunciation. If IRC is carried out, it is sufficient if notification of the decision is made via email. The arbitral tribunal may send the award by e-mail or post it on the website used for the case in question $[2]$.

\section{e) Sentencing}

At the end of the arbitration process, if the arbitration is carried out by more than one person, then the arbitrators will be deliberated. If the arbitrators are located in geographically 
far apart areas, the deliberation will be conducted using e-mail or IRC facilities. This needs to be determined at a certain time for deliberation.

\section{f) Electronic Contracts (E-Contracts)}

Transactions through telecommunications or information technology have a significant impact on international contract law. Contracts no longer have to be subject to pre-existing doctrines. Dispute resolution does not have to be done conventionally. Transactions, contract agreements, and dispute resolution can be carried out through information technology. In general, the form of electronic contracts is standard contracts. This form of contract is difficult to avoid because electronic transactions require fast transactions, in accordance with the nature of the information technology. The main problem with this new form of contract is the issue of protection, security of transactions, and the validity of contracts made through information technology facilities. Another problem that is also difficult to solve is the issue of jurisdiction or competence of the court that will handle disputes arising from the presence of this econtract [3].

\subsection{Alternative Procedures for Online Arbitration Dispute Resolution that Have Been Implemented in the United States and China}

As one of the countries that become benchmarks in economic and technological progress, the researchers chose America and China in carrying out comparisons in the laws adopted in those countries, especially with regard to the application of online alternative arbitration dispute resolutions. The United States is also the first country to develop the internet in trading activities.

\subsection{Online Arbitration in the United States}

In the rapid development of technology, the American people need a dispute resolution that is quick and easy without taking a long time. As a result, that they can get justice without going through a long process. The authorized arbitration institution in the United States is the American Arbitration Association (AAA) which is an alternative dispute resolution service operator. This institution has a role in managing cases from the beginning of the process to the decision. In addition, it also assists in the appointment of mediators and arbitrators.

In practice, the AAA issued additional regulations that have been in effect since 2001 . These additional regulations aim to facilitate parties related to electronic means in arbitration if the parties agree. Among them, it is stated, "In carrying out online arbitration procedures, there is the main concept, namely that every dispute that is made online will create a site for the case. On the site, all files concerning cases and documents submitted by the parties will be stored. Only the American Arbitration Association and its parties have access to the information contained on this site [2]."

The online arbitration agreement in its implementation can be seen from the implementing provisions issued by the AAA which has adopted the agreement in the online form. The online arbitration agreement is made in the form of standard arbitration clauses as follows. "Any controversy or claim arising out of or relating to this contract shall be determined by arbitration in accordance with the international arbitration rules of the international center for dispute resolution." 
Additional regulations also underline the importance of experienced arbitrators in using online arbitration as a means of dispute resolution. "It seems that an important consideration whether to use online arbitration or not will depend on the availability of able, experienced, and trusted arbitrators. However, it is almost impossible to say what coursework would be required to become a good mediator or arbitrator, especially because of the potential variety of cases that they may be asked to decide. Most likely in the future, most online arbitrators will not only be lawyers but will also be specialized in certain types of cases."

Additional rules regarding arbitration agreements are contained in the Supplementary Rules which state as follows. "The purpose of the supplementary procedures for online arbitration is to permit, where the parties have agreed to arbitration under these supplementary procedures, arbitral proceedings to be constructed and resolved exclusively via the internet. The supplementary procedures provide for all party submissions to be made online, and for the arbitrator, upon review of such submission, to render an award and to communicate it to parties via the internet. These supplementary procedures further authorize the parties and the arbiter in certain circumstances to use methods of communication other than the internet."

Furthermore, the online arbitrator qualifications required by the Supplementary Rules are as follows.

a. Having educational qualifications and knowledge of the legal field related to the case they will decide. In addition, an online international arbitrator must comply with international law, in particular the contents of the New York Convention and other international agreements that may have an impact on international commercial disputes.

b. Having experience. For the effectiveness of a decision, they must have competence in the area where they make decisions. Most companies place a high value on experience over education. Online arbitrators can be lawyers and those who have worked as corporate advisors for multinational corporations, have a good education, and possess experience.

c. Honesty and integrity, which are important things that are expected of everyone. An online arbitrator is a professional one who must behave according to a code of ethics. The organizations that employ them will ensure that they have high ethical and professional standards. International online arbitrators should be aware that the use of bribes is a normal way of doing business in many countries around the world, especially in developing countries in Asia, Africa, and Latin America. International online arbitrators should be aware of this situation. They can be approached by one of the disputing parties and must be prepared to deal with these possibilities.

d. Paying attention to every data, fact, and information contained in online media. For conventional arbitrators, the arbitrators have to be good listeners and must pay great attention to a case. In the case of international arbitrators, thoroughness is very important as they have to deal with different parties in different countries, where different laws may apply. In addition, it must also show respect for the parties during dispute handling.

e. Considering the sensitivity of the culture. International arbitrators must decide the problems of the parties who come from various races, languages, and cultures. People from different cultures present information in different ways because their cognitive styles are different.

In online dispute resolution, there are official procedures for the disputing parties to file cases. Neither party gets special rights to make their resolve or to get special treatment because each party must follow the established procedures [4]. Those procedures are as follows [4]. 
a. Submission and initiation, It is starting with the administrative process, in which when a case is submitted by the parties so that it can be processed through arbitration, they must refer to the arbitration provisions and pay the submission fee as determined. After that, the parties will be notified of the deadline for receiving an answer or reply.

b. Selection of arbitrators, After receiving answers from the parties, the AAA selects an arbitrator from their neutral list. The criteria of the parties are used to identify the neutrality of arbitrators with qualifications appropriate to the needs of the case.

c. Initial meeting, this is the first opportunity for the arbitrator and the disputing parties to discuss issues related to the case.

d. Information exchange and preparation, in this stage, the parties prepare their presentations and the arbitrator resolves an impasse regarding information/

e. Audience, this is an opportunity for the parties to present testimony and evidence for the arbitrator.

f. Post-hearing submissions, this stage is an opportunity for the parties to submit additional documents with the permission of the arbitrator.

g. Awards, in this stage, the arbitrator closes the records of the case and issues a decision.

Online arbitration in the United States already has a clear format and provisions, where infrastructure, such as institutions and legal regulations, provides certainty for parties who wish to resolve their disputes through arbitration. This can provide legal certainty for the parties.

\subsection{Online Arbitration in China}

China has had a fairly large and quite complex economy in the world since two thousand years ago. In addition, China has experienced ups and downs. Since entering the economic reform period in 1978, China has experienced the fastest growth in the world. In the business world, the parties prefer to settle out of court. This is because the dispute resolution in the court is not efficient. Undoubtedly, this is inversely proportional to alternative dispute resolution which is more efficient and confidential.

In China, there is an institution known as the China International Economic and Trade Arbitration Commission (CIETAC), which handles cases related to the economy, trade, and other disputes, both contractual and non-contractual based on the agreement of the parties [5]. The authority of CIETAC includes handling international disputes, disputes that occur in the Hong Kong administrative special region, disputes that occur in the Macao administrative region, disputes that occur in Taiwan territory, and domestic disputes.

On 4 November 2014, this commission passed the Online Arbitration Law and it came into force on 1 January 2015. The passage of the Online Arbitration Law was due to the growing share of the e-commerce market in China. With the existence of this law, it can provide legal guarantees for the parties to the dispute. The law states that disputes that can be resolved through online arbitration are disputes arising from economic transactions and other trade transactions based on the agreement of the parties.

The online arbitration agreement is regulated in Article 6 of the China Online Arbitration Law, namely as follows. "An arbitration agreement is either an arbitration clause incorporated in a contract agreed by and between the parties or any other form of a written agreement between the parties providing for the settlement of disputes by arbitration. The arbitration agreement shall be in writing. An arbitration agreement is in writing if it is contained in a tangible form of a document, such as a contract, letter, telegram, telex, facsimile, electronic data interchange (EDI) or e-mail." 
In handling disputes through online media, CIETAC has procedures that regulate the parties that file their cases. The procedure is regulated in Articles $17-40$ which is divided into 4 official procedures. The procedures are as follows.

\section{a) Request for Arbitration, Defense, and Counterclaim}

In this procedure, the arbitral tribunal begins when it receives a request for arbitration from the disputing parties, namely the applicants. The applicants must also meet the requirements at the time of filing for the arbitration process, namely as follows (Article 18 of [5]).

a. Submit a written request for arbitration signed and affixed with a seal by the applicant and/or their authorized representative in accordance with the requirements of the "Arbitration Application Format" and "Arbitration Application Filling Guide" issued by the China International Economic and Trade Arbitration Commission (CIETAC) and can be downloaded at the website of CIETAC online dispute solution center.

b. Attach relevant supporting evidence.

c. Make a payment of arbitration fees in advance.

After all the conditions are met, the commission must notify the parties in writing within 5 days from the date of receipt of the application. If the application does not meet the requirements for arbitration, CIETAC shall notify the parties in writing along with the reasons for the rejection of the application. If the application for arbitration is accepted, this institution must provide a website that can be used by the applicant and respondent in dispute.

If agreed, the parties may submit a defense statement in writing with relevant evidence against the notice of commencement of the arbitration proceedings within 30 days of receipt of the notice of arbitration in accordance with the requirements of the Arbitration Defense Format and the Arbitration Defense Filing Guide.

The defense statement must be signed and affixed with the seal of the respondent or their authorized representative. If agreed by the parties, the applicant, who wishes to file a claim, must do so in writing within the specified time (Article 21 of [5]). If agreed by the applicant and the respondent, the applicant may submit a statement of defense for the respondent to the commission within 20 days from the receipt of the defense statement from the respondent in accordance with the provided format.

\section{b) The Arbitral Tribunal}

After the requirements and procedures are met, the applicant and the respondent appoint an arbitrator or three arbitrators in accordance with the agreement. If agreed, the parties may appoint an arbitrator outside of the available tribunal.

\section{c) Hearing}

The arbitral tribunal issues procedural orders, terms of reference, and other measures in order to increase the speed and efficiency of the arbitration process. In any event, the arbitral tribunal must treat the parties fairly and provide equal opportunities for the parties to present their respective cases. The arbitral tribunal must determine whether the evidence submitted by the parties is admissible and relevant. The evidence submitted by the parties can be in the form of electronic evidence, which is sent, received, and stored electronically or through other similar means. 


\section{d) Arbitral Award}

The decision of the arbitral tribunal may be rendered within 4 months from the date when the arbitral tribunal was established if agreed by the parties. Furthermore, if deemed necessary, the Chairman of CIETAC may extend the trial period with justifiable reasons. The arbitration award must be in writing stating the date when the award is made and the place where the award is made. Furthermore, it must be signed by the arbitrator and officially sealed by the CIETAC arbitrator.

\subsection{Possibility of the Application of Online Arbitration in Indonesia based on Indonesia's Law No. 30/1999 Concerning Arbitration and Alternative Dispute Resolution}

\subsubsection{Online Arbitration and Online Dispute Resolution}

The implementation of online arbitration can indeed be carried out from the tribunal which makes the decision able to carry out its duties properly. The arbitration award is a binding decision. The arbitrators can have strong confidence that the court will enforce its decisions. Even though the conviction is great, there are certain criteria that must be met in order for a decision to be enforced by the court.These criteria are found in international conventions, such as the New York convention and the national laws of each country regarding arbitration. In most cases, issues that arise regarding online arbitration are arbitration agreements, arbitration procedures, and arbitral awards.

\subsubsection{Internet}

It is a difficult issue to discuss legal issues in the world of the internet which is a new environment, especially in the discussion of online arbitration and online alternative dispute resolutions without having an idea of this new environment, what this new environment actually looks like, where it comes from, how it can be brought together, and how it works.

\section{a) Internet Protocol}

Every computer connected to the internet has the ability to perform various tasks in a very short time. The relationship of millions of computers of various very complex applications can be implemented directly. Any internet transmission, whether sending electronic mail (e-mail), visiting websites, downloading video or audio files, applies what is referred to as the internet protocol hereinafter referred to as IP. It was discovered by Robert Kahn and Vint Cerf in 1974. IP is a communication scheme that defines how data is sent across the network. IP has two standard elements that become keys in every transmission. The first is a general method of breaking each transmission into pieces of data called "packets". The second is a global observation system. IP allows each computer to connect to the internet by using a unique address and a description of the data packets that can be sent to those addresses. IP dictates two simple rules, namely as follows.

1. Every computer connected to the internet must be reachable through an address in the form of numbers in a certain form, namely four bits. This address is referred to as an Internet Protocol Address or IP Address. For example, the IP Address for the homepage of Google is 216.239.51.100. This IP address must exist in order to connect to the internet. 
2. Every computer connected to the internet must be able to receive packets consisting of 24 - 32 Byte Headers and one packet size up to 576 bytes. The header contains information on the origin and destination addresses of each packet and the total number of packets.

Since the internet is so simple, several useful features are not covered by the protocol. A key feature not included in IP is delivery assurance. IP messages sent from one computer to another are first broken up into small packets. Each of them is labeled with the machine address of the destination computer. After that, the computer sends data to another computer connected to the internet that appears in the destination address until the data reaches the destination address.

However, there is no guarantee that the data packet will arrive at the destination address. It is also possible that the data packet reaches the destination address but is incomplete or even damaged. To ensure that this is successful, it is not the job of IP. The task is carried out by another protocol, namely the Transmission Control Protocol (TCP). TCP is above IP with the task of ensuring that all packets sent from one machine to another are received properly and at the correct address. If a packet is lost during transmission, the destination machine uses TCP to request the sending machine to resend the lost packet and notify the sending machine when the returned packet arrives at its destination. As TCP and IP are used together, they are often simply referred to as TCP/IP. The software that implements TCP/IP is called a "stack". This means that the sending computer uses IP to break the data into packets in the original format.

\section{b) Internet Protocol Address}

IP addresses are distributed hierarchically. The peak is occupied by the IANA (Central Registry) which then allocates the regional registry places for APNIC, ARIN, LACNIC, and RIPE NCC. This regional registry then allocates it to the major internet service providers (ISPs). Large ISPs then allocate it to smaller internet service providers and then to smaller consumer networks.

\section{c) Methods of Communication through the Internet}

There are various ways of communicating using the internet, namely as follows.

1. One-to-one communication like e-mail.

2. One-person communication with multiple recipients like online arbitration.

3. Delivery of databases of messages like the use of USENET newsgroups.

4. Real-time communication like the use of Internet Relay Chat.

5. Searching information via remote like using FTP, Gopher, and the World Wide Web.

Most of these communication methods can be used to transmit text, data, computer programs, audio, images, and video.

\section{d) The Basics of the World Wide Web (WWW)}

It is a collection of documents stored in different computers and connected to the internet. Documents containing various kinds of information are stored in various formats, such as text, images, audio, video, and others if any. The most essential element of a web is that every document contained in it has a specific address. Web owners have the freedom to choose whether to make their website open to all internet users or to make it closed only to users who have obtained prior approval. Kompas, for example, operates a website that can be accessed 
by internet users freely. On the other hand, the New York Times requires internet users to fill in their personal data first before viewing the information available on its website.

\section{e) General Standard}

Links on the web use a basic language called Hyper Text Mark-up Language (HTML) and a general language for exchanging documents on the web called HyperText Transfer Protocol (HTTP). Although the information can be created in a variety of formats and stored on computers that are not compatible with each other, the basic standards of the web provide a basic set of standards that enable the exchange and communication of information.

The web is also a distributed system where there is no centralized control. The web is designed in such a way that anyone with a computer containing information can become part of the web by connecting a computer to the internet and running WWW-compatible software. No single organization controls membership on the web. In addition, there is no control that can block access to a document on the internet. The success achieved with the existence of this web has brought the idea that this can actually be used to manage dispute resolution as an alternative to traditional dispute resolution [2].

\subsubsection{Online Arbitration Agreement}

The arbitration agreement is an additional agreement or known as "accessoir" because the nature of the clause is only in addition to the main agreement and does not affect the implementation of the fulfillment of the main agreement. Therefore, the cancellation of the arbitration agreement does not result in the cancellation of the main agreement but the cancellation of the main agreement directly results in the void and non-functioning of the arbitration agreement. Online arbitration in practice uses media that are entirely in the form of electronic information so that the parties involved in online contracts do not meet in person. The difference between an online agreement and a conventional agreement is that for the online agreement, the offer and acceptance are carried out in the electronic or digital form.

Online agreements are generally non-faced. In other words, they do not require a physical presence. For example, on the website of 92, offers are carried out through mailing lists and newsgroups. In online arbitration, case registration, selection of arbitrators, preparation, submission of documents, deliberation of arbitrators, decision making, and notification of a decision are made online. The arbitration agreement is declared valid if it meets the subjective and objective requirements contained in Article 1320 of the Indonesian Civil Code, namely as follows.

a. Agree on those who bind themselves.

b. The ability to make an engagement.

c. A certain thing.

d. A cause.

Points (a) and (b) are subjective requirements because the two conditions relate to the people or legal subjects who make the agreement. For points (c) and (d), the last condition is called the objective conditions because both are related to the agreement itself or the object of the act committed. If the first and second elements (subjective elements) are not fulfilled, then the agreement can be canceled. However, if the third and fourth elements are not fulfilled (the objective elements), then the agreement is null and void.

\section{a) Agree on Those Who Bind Themselves}


It means that the parties who make it must agree. They agree on the things that have been agreed upon. What the will of one party is will be also desired by the other parties. They want the same thing reciprocally with no coercion. Agreement means that the parties must state each other's will to make an agreement. The statement of one party is "the same" as the statement of the other party. In connection with the statement of "will is not always in accordance with the will", there are several theories attempting to explain this phenomenon [6].

1. Theory of Will (Wilstheorie), it is a teaching that gives birth to an agreement because of the real will of the parties.

2. Theory of Statements (Verklaringstheorie), it is a teaching that what makes an agreement is not the will but the statement of the will of the person who declares it.

3. Theory of Belief (Vetrouwenstheorie), The agreement will occur if there is an objective statement that can be trusted. Agreements arise when there is acceptance of the offer. Therefore, the important moment is acceptance.

\section{b) Ability to Make an Engagement}

Based on Article 1329 of the Indonesian Civil Code, "Everyone is capable of entering into engagements even if they are not declared incompetent by law. The requirement for the competence of the parties to make an engagement means that the party making the agreement must be legally competent." In principle, everyone who is mature and in sound mind is capable according to the law. However, there are people who according to the law are declared incompetent to carry out legal actions, namely as follows.

1. People who are not yet mature, namely children who have not reached the age of 18 years or those who have never been married (Article 1330 of the Indonesian Civil Code in conjunction with Article 47 of Indonesia's Marriage Law No. 1/1974).

2. People under guardianship, namely adults but in a state of stupidity, madness, dark eyes, and wastefulness (Article 1330 of the Indonesian Civil Code in conjunction with Article 433 of the Indonesian Civil Code).

3. People who are prohibited by law from carrying out certain legal actions, for example, people who are declared bankrupt (Article 1330 of the Indonesian Civil Code in conjunction with Indonesia's Bankruptcy Law).

Therefore, people who are capable of carrying out legal actions are people who are mature, of sound mind, and not prohibited by law from carrying out certain legal actions. In a transaction that is carried out online, it is impossible to have a direct meeting between the seller and the buyer. To find out whether the buyer is capable of entering into an agreement, it can be assured by confirming their credit card to the bank. It is because, to make online transaction payments, a credit card or e-cash is needed in a personal name, meaning that when making a credit card, ones have to go through a card making procedure including showing an ID card and having to pass the age limit for making credit cards. This can also be used in disputes that use online arbitration for settlement, namely by requesting confirmation from the bank about the identity of the parties who are charged with case administration fees.

\section{c) A Certain Thing}

A certain thing is the third condition for the validity of the agreement. It is related to what (object) is agreed in an agreement. Goods or objects must be specified type. The status of the goods, whether already exist or are in the hands of the buyer when the agreement is made, is 
not required by law. In an arbitration agreement, the object is the principal agreement. Therefore, the main target in the arbitration agreement is the dispute that occurs in the main agreement which is then resolved in the arbitration forum. For the validity of the arbitration forum, the objects contained in the main agreement must be objects allowed by law, namely as follows.

1. The goods which are the object of the contract must be goods that can be traded (see Article 1332 of the Indonesian Civil Code).

2. When the contract is made, the minimum type of the goods has been determined (see Article 1333 Paragraph 1 of the Indonesian Civil Code).

3. The amount of the goods may be indefinite, provided that the amount can then be determined or calculated (see Article 1334 Paragraph 2 of the Indonesian Civil Code).

4. The goods can also be new goods that will be available at a later date (see Article 1334 Paragraph 1 of the Indonesian Civil Code).

\section{d) Halal Cause}

The halal cause needs more explanation to what is meant by a halal cause is the content of the agreement. For example, in a sale and purchase agreement, one party wants money and the other party wants ownership rights to the goods. This reason is a halal cause, meaning that the contents of the agreement do not deviate from the provisions of the applicable legislation and do not deviate from the norms of order and decency.

The cause of an agreement is what the parties want to achieve by doing the agreement, called the purpose of the agreement. In buying and selling activities, the reason for the agreement to be made is that the buyer wants to get the goods and the seller wants to get the money. Referring to Articles 1335 and 1337 of the Indonesian Civil Code, the halal causes are as follows.

1. Causes that are not prohibited or contrary to the law like disputes regarding trafficking in children or women.

2. Causes that are contrary to morality like a trade dispute regarding pornography.

3. Causes that are in accordance with public order, such as illicit trade in weapons or terrorism.

\section{e) Engagement Legal System}

The engagement legal system is open, meaning that everyone is free to enter into agreements, both those that have been regulated and those that have not been regulated by law. This can be concluded from the provisions contained in Article 1338 Paragraph 1 of the Indonesian Civil Code, namely "All agreements made legally are valid as law for those who make them." The provisions of Article 1338 Paragraph 1 of the Indonesian Civil Code provide freedom for the parties to:

1. Make or not make an agreement,

2. Make an agreement with anyone,

3. Determine the contents of the agreement, its implementation, and its requirements, and

4. Determine the form of the agreement, namely written or oral agreement.

According to the history of its development, the engagement legal system was originally a closed system. This means that the parties are related to the meaning contained in the Law. This is due to the doctrine of legalism which views that there is no law outside the law. This can be seen in the various decisions of the Hoge Raad from 1910 to 1919 [7]. 


\subsubsection{Online Arbitration as an Alternative for Dispute Resolution}

The development of the business sector and the increasingly rapid transfer of technology, especially during the COVID-19 pandemic, have positive impacts. One of them is accelerating the process of marketing products to the wider community. However, on the other hand, it can lead to differences in perceptions and disputes because one of the parties is in default of the agreed contract and certainly results in a loss for one of the parties. Several alternative dispute resolutions, such as consultation, negotiation, mediation, conciliation, or peace, cannot be achieved. For this reason, the parties can propose their settlement efforts through an arbitration institution. Therefore, arbitration can be considered to be the final alternative dispute resolution institution for the parties.

Arbitration is a way of settling a civil dispute outside the general court based on an arbitration agreement made in writing by the disputing parties. Arbitration is often chosen because it has many superior factors that lead to a dispute resolution method that is considered better than other dispute resolution method. Technological developments continue to advance. This also results in the possibility that dispute resolution through arbitration can be carried out online, which will later help the parties, both in terms of speed of time and cost-effectiveness. For the parties between countries, no passport or visa is required to enter other countries through a virtual world built over the internet. Because of the convenience of this information technology, the internet is not only used as a mere means of correspondence but also for trade. The commerce carried out electronically is known as e-commerce [8].

Efforts to resolve online arbitration disputes have begun to be recognized and implemented in developed countries such as America, Britain, Canada, China, and several countries in Europe. In Indonesia, online arbitration is a new thing and has not been regulated in a special regulation. Regulations on arbitration in Indonesia are contained in the Law of Arbitration and Alternative Dispute Resolution. However, in the law, there is no regulation regarding arbitration conducted online.

In the law, there are several articles that explicitly explain that online arbitration can actually be applied in Indonesia. For example, the procedure for online arbitration can be carried out based on the provisions in Article 4 Paragraph 3, as follows [9]. "In the event that it is agreed that dispute resolution is carried out through arbitration, it occurs in the form of an exchange of letters. Therefore, the sending of telex, telegram, facsimile, e-mail, or in other forms of communication means must be accompanied by a note of receipt by the concerned parties."

From the provisions above, it can be concluded that the implementation of online arbitration is possible if there is a prior agreement from the parties to conduct online arbitration. In the agreement, the parties add a clause for settlement through online arbitration. Notification regarding the entry into force of the terms of arbitration is regulated in Article 8 of the Law of Arbitration and Alternative Dispute Resolution, as follows [9].

a. In the event that a dispute arises, the applicant must notify the respondent by registered letter, telegram, telex, facsimile, e-mail, or expedition book that the terms of the arbitration held by the applicant or the respondent apply.

b. The notification letter to hold the arbitration as referred to in Paragraph 1 clearly contains as follows.

1) The names and addresses of the parties.

2) Appointment of the use of clauses or arbitration agreements to be enforced.

3) The agreement or issue in dispute.

4) The basis of the claim and the amount demanded if any. 
5) The desired method of settlement of the case.

6) An agreement entered into by the parties regarding the number of arbitrators or if no such agreement has ever been entered into, the applicant may propose an odd number of arbitrators.

The arbitration institution determines whether to carry out the online process or not because it only accepts cases related to online activities, such as e-commerce default, copyright infringement, patents in cyberspace, and defamation. In this case, procedural rules regarding online arbitration are drawn up. If the parties designate dispute resolution through a certain arbitration institution, the parties automatically also agree to apply the online procedures provided by the service provider concerned.

In the provisions of Article 31 Paragraph 1 of the Law of Arbitration and Alternative Dispute Resolution, it is stated as follows. "The parties to a firm and written agreement are free to determine the arbitration procedure used in the examination of the dispute as long as it does not conflict with the provisions of this law."

Based on this article, the parties can determine the form of the event in the arbitration process, including conducting online arbitration. Furthermore, the provision of Article 31 Paragraph 2 of the Law of Arbitration and Alternative Dispute Resolution states as follows. "In the event that the parties do not determine independently the provisions regarding the arbitration procedure to be used in the examination and the arbitrator or arbitral tribunal has been formed in accordance with Article 12, Article 13, and Article 14, all disputes whose settlement is submitted to the arbitrator or arbitral tribunal will be examined and decided according to the provisions of this law."

In Article 31 Paragraph 2, if the parties do not choose to use a certain arbitration procedure, the arbitration process will follow the provisions of the Law of Arbitration and Alternative Dispute Resolution. If there are parties later who experience e-commerce disputes and want to resolve the dispute through online arbitration even though there are no implementing rules, they can still resolve the dispute by online arbitration. This is based on the procedural provisions contained in Articles 27-64 of Indonesia's Law Number 30 of 1999 which contains no article that states that in the event according to the law, the parties must face to face physically.

In the arbitration process regulated by the law, the parties are not required to be present during the arbitration process so that not being able to meet face to face in the online arbitration process is not a problem. In addition, with the presence of Article 4 paragraph 3, it remains open to the possibility that the parties can resolve their disputes online.

Online arbitration in Indonesia is in accordance with and does not conflict with existing laws and regulations. Although the legal basis for its implementation already exists, the problem is that there are no implementing regulations that regulate how it is carried out. If the arrangements for the implementation of online arbitration are left to the parties, it is feared that there are no standards regarding the effective and efficient implementation of online arbitration. Article 34 of the law states as follows.

a. Settlement of disputes through arbitration may be carried out using national or international arbitration institutions based on the agreement of the parties.

b. Settlement of disputes through the arbitration institution as referred to in Paragraph 1 shall be carried out according to the rules and procedures of the chosen institution unless otherwise stipulated by the parties.

Based on the article above, arbitration through the arbitration institution will be determined by the arbitration institution concerned unless otherwise determined by the parties. This 
enables the arbitral tribunal to apply online arbitration by determining the online arbitration procedure with the consent of the parties.

The core regulatory principles are meant to ensure the standard quality of justice in online dispute resolution which is complied with. The core principles can be summarized in the following [10].

a. The process must be transparent;

b. The dispute resolution institution and the neutral must be impartial and independent;

c. The procedure must be handled swiftly;

d. The system must be easily accessible;

e. The procedure must be globally fair;

f. In the field of $\mathrm{B} 2 \mathrm{C} 96$, preference should be given to outcomes that bind only the supplier, while B2B 97 outcomes should preferably be binding on both parties.

Based on the explanation above, it can be concluded that the principle of regulation in online arbitration must meet the elements of justice, namely as follows.

a. The online arbitration process must be transparent.

b. The arbitral tribunal must be neutral and independent.

c. The procedure must be carried out quickly.

d. The online arbitration system should be more easily accepted by the public.

e. Procedures must be globally fair.

f. In entrepreneur-to-consumer transactions, it is preferable to give binding on the entrepreneur, where the entrepreneur to the entrepreneur should be more binding on both parties.

\subsection{Conclusions and Recommendations}

\subsubsection{Conclusions}

Based on the results and discussion, it can be concluded several things regarding alternative dispute resolution through online arbitration according to the Law of Arbitration and Alternative Dispute Resolution applied in Indonesia, namely as follows.

a. The presence of implementing rules regarding online arbitration in the United States and China indicates that there is a guarantee and legal certainty for the disputing parties in economic transactions or other disputes. In choosing which dispute resolution efforts will be chosen by the parties, the parties are given freedom according to the agreement of the parties who bind themselves to each other in an agreement.

b. Explicit arrangements regarding online arbitration as an alternative dispute resolution can be applied in Indonesia because the results of the analysis are in line with and do not conflict with existing laws and regulations, especially the Law of Arbitration and Alternative Dispute Resolution. The presence of online arbitration can provide opportunities for the business world to resolve disputes without worrying about disrupting the company's operational processes in general. Online arbitration for the business world is the right choice and in line with the spirit of growing business ethics for entrepreneurs.

\subsubsection{Recommendations}

On the basis of the conclusions that have been mentioned, the following are several recommendations as a solution to the main problems that have been proposed. The internet and information technology play a very important role in the dispute resolution process. 
Documents can be transmitted quickly to arbitrators and other parties at a low cost. The parties can save costs because they do not need to attend a trial in a court that may be located far from their place of residence.

a. It is expected that the Supreme Court will make implementing regulations regarding alternative dispute resolution through online arbitration in order to create legal legitimacy and appoint an institution that acts as law enforcers regarding online arbitration, especially during the COVID-19 pandemic.

b. It is expected that the Government of Indonesia can provide the facilities and infrastructure needed so that online arbitration can be implemented in Indonesia, especially related to the distribution of internet networks. As a result, all citizens can benefit from advances in information technology.

\section{References}

[1] R. Ginting, Transaksi Bisnis \& Perbankan Internasional. Jakarta: Universitas Trisakti, 2014.

[2] P. Siburian, Arbitrase Online. Jakarta: Djambatan, 2004.

[3] H. Adolf, Dasar-dasar Hukum Kontrak Internasional. Bandung: PT Refika Aditama, 2007.

[4] A. J. Cakrawala, Penerapan Konsep Hukum Arbitrase Online di Indonesia. Yogjakarta: Rangkang Education, 2015.

[5] C. I. E. and T. A. Commission, "China International Economic and Trade Arbitration Commission CIETAC Arbitration Rules," China Counc. Promot. Int. Trade/China Chamb. Int. Commer., 2015, [Online]. Available: http://www.cietac.org/Uploads/201607/5795f078aa6d5.pdf.

[6] S. R, Pokok-Pokok Hukum Perikatan, Cetakan ke. Bandung: Putra A Bardin, 1999.

[7] S. HS, Pengantar Hukum Perdata Tertulis. Jakarta: Sinar Grafika, 2001.

[8] R. Hill and I. Walden, "Electronic Commerce can be defined as commercial activities conducted through an exchange of information generated, stored, or communicated by electronical, optical or analogues means, including EDI, E-mail, and so forth (." 1996.

[9] The Republic of Indonesia, Undang-Undang Nomor 30 Tahun 1999 Tentang Arbitrase. 1999.

[10] G. Kaufmann and K. T. Schultz, Online Dispute Resolution: Challenges for Contemporary Justice. The Hague: Kluwer Law International, 2004. 